\title{
Single inhaler extrafine triple therapy in uncontrolled asthma (TRIMARAN and TRIGGER): two double-blind, parallel-group, randomised, controlled phase 3 trials DOI:
}

10.1016/S0140-6736(19)32215-9

\section{Document Version}

Accepted author manuscript

Link to publication record in Manchester Research Explorer

Citation for published version (APA):

Virchow, J. C., Kuna, P., Paggiaro, P., Papi, A., Singh, D., Corre, S., Zuccaro, F., Vele, A., Kots, M., Georges, G., Petruzzelli, S., \& Canonica, G. W. (2019). Single inhaler extrafine triple therapy in uncontrolled asthma (TRIMARAN and TRIGGER): two double-blind, parallel-group, randomised, controlled phase 3 trials. The Lancet, 394(10210), 1737-1749. https://doi.org/10.1016/S0140-6736(19)32215-9

\section{Published in:}

The Lancet

\section{Citing this paper}

Please note that where the full-text provided on Manchester Research Explorer is the Author Accepted Manuscript or Proof version this may differ from the final Published version. If citing, it is advised that you check and use the publisher's definitive version.

\section{General rights}

Copyright and moral rights for the publications made accessible in the Research Explorer are retained by the authors and/or other copyright owners and it is a condition of accessing publications that users recognise and abide by the legal requirements associated with these rights.

\section{Takedown policy}

If you believe that this document breaches copyright please refer to the University of Manchester's Takedown Procedures [http://man.ac.uk/04Y6Bo] or contact uml.scholarlycommunications@manchester.ac.uk providing relevant details, so we can investigate your claim.

\section{OPEN ACCESS}




\section{Title}

2 Single inhaler extrafine triple therapy in uncontrolled asthma: two randomised, double-blind, 3 parallel group, controlled trials (TRIMARAN and TRIGGER)

\section{Authors}

5 Prof. Johann Christian Virchow MD, ${ }^{1 *}$ Prof. Piotr Kuna MD, ${ }^{2}$ Prof. Pierluigi Paggiaro MD, ${ }^{3}$

6 Prof. Alberto Papi MD, ${ }^{4}$ Prof. Dave Singh MD, ${ }^{5}$ Sandrine Corre MSc, ${ }^{6}$ Florence Zuccaro

7 MSc, ${ }^{6}$ Andrea Vele MSc, ${ }^{6}$ Maxim Kots MD, ${ }^{6}$ George Georges MD, ${ }^{6}$ Stefano Petruzzelli MD, ${ }^{6}$

8 Prof. Giorgio Walter Canonica MD*

9 *Drs Virchow and Canonica were principal investigators of TRIMARAN and TRIGGER,

10 respectively, and contributed equally to the development of this manuscript.

11 1. Universitätsmedizin Rostock, Zentrum für Innere Medizin, Abteilung für Pneumologie,

12 Rostock, Germany

13 2. Division of Internal Medicine, Asthma and Allergy Medical University of Łódź, Poland

14 3. Department of Surgery, Medicine, Molecular Biology, and Critical care, University of Pisa,

15 Pisa, Italy

16 4. Section of Cardiorespiratory and Internal Medicine, Department of Medical Sciences,

17 University of Ferrara, Ferrara, Italy

18 5. Medicines Evaluation Unit, The University of Manchester, Manchester University NHS

19 Foundation Trust, Manchester, UK

20 6. Global Clinical Development, Chiesi Farmaceutici SpA, Parma, Italy

21 7. Humanitas University and Research Hospital, Center of Personalized Medicine: Asthma

22 and Allergy, Milan, Italy 


\section{Corresponding author}

2 J Christian Virchow, Universitätsmedizin Rostock, Zentrum für Innere Medizin, Medizinische

3 Klinik, Abteilung Pneumologie \& Interdisziplinäre Internistische Intensivmedizin, Ernst-

4 Heydemann-Str. 618057 Rostock, Germany

$5 \quad$ Email: j.c.virchow@med.uni-rostock.de

6 Phone: +49 3814947460

7 Word count (manuscript body only): 4496 (maximum 4500)

8

9 


\section{Abstract}

\section{Background}

3 No studies have evaluated the efficacy of single-inhaler triple therapy in asthma. These two studies compared the single inhaler extrafine combination of beclometasone dipropionate

5 (inhaled corticosteroid), formoterol fumarate (long-acting $\beta_{2}$-agonist), and glycopyrronium

6 (long-acting muscarinic antagonist; BDP/FF/G) versus BDP/FF.

\section{Methods}

8 Two randomised, parallel-group, double-blind, active-controlled studies. Eligible patients 9 were adults with uncontrolled asthma, history of $\geq 1$ exacerbation, and previously treated with inhaled corticosteroid (TRIMARAN, medium-dose; TRIGGER, high-dose) plus long-acting $\beta_{2}$-agonist. After two weeks receiving BDP/FF (TRIMARAN, 100/6 $\mu \mathrm{g} ;$ TRIGGER, 200/6 $\mu \mathrm{g}$ ), patients were randomised (stratifying by country) to 52 weeks with BDP/FF/G 100/6/10 $\mu$ g or

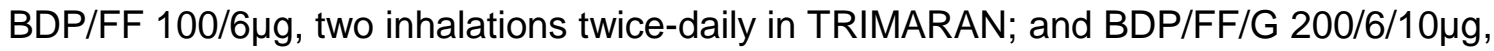

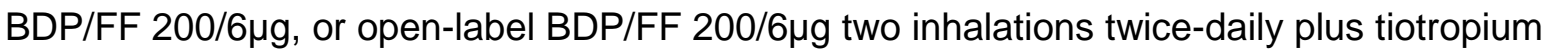
2.5 $\mu \mathrm{g}$ two inhalations once-daily in TRIGGER. Co-primary endpoints (BDP/FF/G vs BDP/FF) were: pre-dose $\mathrm{FEV}_{1}$ at Week 26; rate of moderate-to-severe exacerbations over 52 weeks. Key secondary endpoints included severe exacerbation rate over 52 weeks (using pooled data). ClinicalTrials.gov: NCT02676076, NCT02676089.

\section{Findings}

Between February 2016 and May 2018, 1155 patients in TRIMARAN received BDP/FF/G $(\mathrm{N}=579)$ or BDP/FF (N=576); between April 2016 and May 2018, 1437 patients in TRIGGER received BDP/FF/G (N=573), BDP/FF (N=576) or BDP/FF+tiotropium (N=288). BDP/FF/G improved Week 26 pre-dose $\mathrm{FEV}_{1}$ by $57 \mathrm{~mL}(95 \% \mathrm{Cl} 15-99 ; \mathrm{p}=0.0080)$ and $73 \mathrm{~mL}(26-120$; $p=0.0025)$ vs BDP/FF in TRIMARAN and TRIGGER, respectively, with reductions in moderate-to-severe exacerbation rate of $15 \%$ (rate ratio $0.846[0 \cdot 725-0.987] ; p=0.0331$ ) and $12 \%(0.880[0.751-1.030] ; p=0.1102) . B D P / F F / G$ also reduced the severe exacerbation 
1 rate (pooled analysis) vs BDP/FF (0.770 [0.636-0.933]; $p=0.0076)$. Adverse events were

2 reported by 410-431 (72-75\%) patients with BDP/FF/G, 443-455 (77-79\%) with BDP/FF

3 and $210(73 \%)$ with BDP/FF+tiotropium.

\section{Interpretation}

5 In uncontrolled asthma, the addition of a long-acting muscarinic antagonist to inhaled

6 corticosteroid plus long-acting $\beta_{2}$-agonist therapy improves lung function and reduces severe

7 exacerbations.

\section{Funding}

9 Chiesi Farmaceutici SpA.

\section{Keywords}

12 Combination drug therapy; asthma; respiratory function tests; exacerbation 


\section{Research in context}

\section{Evidence before this study}

3 We searched PubMed for articles published before 4 April 2019, using the search term "Drug

4 Therapy, Combination"[MeSH Terms] OR triple AND asthma AND trial NOT theophylline

5 NOT montelukast, with no limits applied. Of the 1068 hits, eight present data from clinical

6 trials that evaluated the efficacy of triple therapy comprising an inhaled corticosteroid plus a

7 long-acting $\beta_{2}$-agonist plus a long-acting muscarinic antagonist. Of these, six report data in

8 adults (the other two report data in children or adolescents), one of which was a short-term

9 (four week) study, one reports pooled safety data, and one reports subgroup analyses of studies presented in another manuscript. The remaining three manuscripts report data from studies in which the long-acting muscarinic antagonist tiotropium was added as a free combination to any inhaled corticosteroid and long-acting $\beta_{2}$-agonist. The first of these manuscripts presents data from two 48-week studies, in which the addition of tiotropium to high-dose inhaled corticosteroid plus long-acting $\beta_{2}$-agonist delayed the time to first asthma exacerbation and reduced the overall risk of these events, with improvements in lung function. The second manuscript focuses on the long-term (52-week) safety profile of the addition of tiotropium to inhaled corticosteroid plus long-acting $\beta_{2}$-agonist, which was similar to inhaled corticosteroid plus long-acting $\beta_{2}$-agonist alone. In the third manuscript, the addition of tiotropium improved airflow limitation and reduced airway wall thickness after 48 weeks. All three studies evaluated the effect of tiotropium plus inhaled corticosteroid plus long-acting $\beta_{2}$-agonist therapy in patients with spirometric persistent airflow limitation (ratio of forced expiratory volume in 1 second to forced vital capacity $<0 \cdot 7)$.

\section{Added value of this study}

TRIMARAN and TRIGGER are the first studies to evaluate the relative efficacy and safety of single-inhaler triple therapy with those of inhaled corticosteroid plus a long-acting $\beta_{2}$-agonist in adults with asthma - and in particular are the first long-term studies conducted in patients 
1 who had no requirement to demonstrate persistent airflow limitation following short-acting $\beta_{2^{-}}$

2 agonist use.

\section{Implications of all the available evidence}

4 The combination of a long-acting muscarinic antagonist with an inhaled corticosteroid plus a

5 long-acting $\beta_{2}$-agonist therapy in adults with uncontrolled asthma results in improved lung

6 function. In large, longer-term studies triple therapy has a positive impact on severe

7 exacerbations. 


\section{Introduction}

2 The goals of asthma management are to achieve symptom control and to avoid future risks, especially of exacerbations. ${ }^{1}$ Asthma is characterised by the presence of chronic airway inflammation, and as a consequence inhaled corticosteroids are the mainstay of therapy. ${ }^{1}$

5 Many patients are able to achieve good disease control, especially from an inhaled corticosteroid/long-acting $\beta_{2}$-agonist combination. ${ }^{2}$ However, until recently limited options were available for patients who could not achieve controlled asthma with such combinations.

8 The addition of the long-acting muscarinic antagonist tiotropium to inhaled corticosteroid/long-acting $\beta_{2}$-agonist therapy has been shown to improve lung function, and in longer studies (48-week duration) reduce the risk of exacerbations in patients with asthma, although in a subgroup of patients with persistent airflow limitation. ${ }^{3-5}$ However, this requires patients to use two different inhalers, of different design and with different instructions for use - and often with different dosing regimens. This is not only inconvenient for patients and healthcare providers who provide instruction on correct inhaler use, but can negatively impact treatment adherence and persistence..$^{6-9}$ A single-inhaler triple therapy consisting of an extrafine formulation (i.e., with mass median aerodynamic diameter $<2 \mu \mathrm{m}$ ) of the inhaled corticosteroid beclometasone dipropionate (BDP), the long-acting $\beta_{2}$-agonist formoterol fumarate (FF), and the long-acting muscarinic antagonist glycopyrronium (G) delivered via a pressurised metered-dose inhaler (pMDI) is in development for patients with asthma. Such extrafine formulations result in improved deposition in the small airways, ${ }^{10}$ which is potentially important given that asthma patients with significant small airways dysfunction tend to have poorer asthma control and quality of life, and are at increased exacerbation risk. ${ }^{11}$

This manuscript describes the results of two Phase III, 52-week studies comparing the efficacy and safety of medium-strength (100/6/10 $\mu \mathrm{g}$; TRIMARAN) and high-strength (200/6/10 $\mu \mathrm{g}$; TRIGGER) BDP/FF/G with that of the respective strengths of BDP/FF in patients with asthma poorly controlled on medium-dose (TRIMARAN) or high-dose 
1 (TRIGGER) inhaled corticosteroid/long-acting $\beta_{2}$-agonist therapy. These are the first studies

2 to evaluate single-inhaler triple therapy in a broad asthma population not restricted to those

3 with persistent airflow limitation. 


\section{Methods}

\section{Study design}

3 Both studies were randomised, parallel-group, double-blind and active controlled. The main

4 difference between them was the inhaled corticosteroid dose received prior to and during the

5 study, with patients in TRIMARAN receiving a medium dose, and patients in TRIGGER

6 receiving a high dose (see 'Patients' below).

7 Patients who met the inclusion and exclusion criteria at screening (Visit 1) had their asthma

8 maintenance therapy switched to extrafine BDP/FF 100/6 $\mu \mathrm{g}$ in TRIMARAN and 200/6 $\mu \mathrm{g}$ in

9 TRIGGER, two inhalations twice daily via pressurised metered-dose inhaler for a two-week open-label run-in period. At the end of the run-in period, patients in TRIMARAN were randomised 1:1 to either (1) continue BDP/FF 100/6 $\mu$ g two inhalations twice daily, or (2) to receive extrafine BDP/FF/G 100/6/10 $\mu \mathrm{g}$, two inhalations twice daily via pressurised metered-dose inhaler. Patients in TRIGGER were randomised 2:2:1 to (1) continue BDP/FF $200 / 6 \mu \mathrm{g}$ two inhalations twice daily, or to receive (2) extrafine BDP/FF/G 200/6/10 $\mu \mathrm{g}$ two inhalations twice daily via pressurised metered-dose inhaler or (3) open-label BDP/FF 200/6 $\mu \mathrm{g}$ two inhalations twice daily via pressurised metered-dose inhaler plus tiotropium $2.5 \mu \mathrm{g}$ two inhalations once daily via soft mist inhaler $\left(\right.$ Respimat $\left.^{\circledR}\right)$. Over the 52 -week treatment period, patients attended visits at Weeks 4, 12, 26, 40 and 52. Salbutamol via pressurised metered-dose inhaler was permitted as rescue medication, but not within $6 \mathrm{~h}$ prior to any visit.

The studies were approved by the ethics committee or institutional review board at each site and were performed in accordance with the Declaration of Helsinki and the International Conference on Harmonization Good Clinical Practice (ICH/CPMP/135/95). There were no substantial protocol amendments that impacted any randomised patients. The two protocols had one substantial amendment to the inclusion criteria - to clarify that any long-acting $\beta_{2^{-}}$ 
1 agonist was permitted as prior medication, providing it was taken at an approved daily dose

2 that was clinically comparable to formoterol $24 \mu \mathrm{g}$, salmeterol $100 \mu \mathrm{g}$ or vilanterol $25 \mu \mathrm{g}$.

\section{Patients}

4 Patients were to be aged 18 to 75 years, inclusive, with a documented history of asthma for

5 at least one year and that was diagnosed prior to the age of 40 years, pre-bronchodilator

$6 \mathrm{FEV}_{1}<80 \%$ predicted normal value, and a change in $\mathrm{FEV}_{1}$ of $>12 \%$ and $>200 \mathrm{~mL} 10-15 \mathrm{~min}$

7 after inhaling salbutamol $400 \mu \mathrm{g}$. Patients were to have uncontrolled asthma (Asthma

8 Control Questionnaire-7 [ACQ-7] $\geq 1 \cdot 5)$, with a history of at least one exacerbation requiring

9 treatment with systemic corticosteroids or emergency department visit or in-patient hospitalisation in the previous 12 months, and were receiving a stable dose of an inhaled corticosteroid plus a long-acting $\beta_{2}$-agonist for at least four weeks prior to entry (TRIMARAN: medium inhaled corticosteroid dose; TRIGGER high dose; see the supplement for the dose equivalents).

Key exclusion criteria were: history of near fatal asthma or a past intensive care unit hospitalisation for asthma that may place the patient at risk; a severe exacerbation in the four weeks prior to entry or during the run-in period; any other significant lung disease that may interfere with study evaluations; current smokers or ex-smokers with $\geq 10$ pack-years exposure or who stopped smoking one year or less prior to screening; treatment with monoclonal antibodies or other biological drugs; clinically significant cardiovascular conditions or laboratory abnormalities; or unstable concurrent disease that may impact efficacy or safety. The full inclusion and exclusion criteria and non-permitted asthma medications are listed in the supplement.

\section{Randomisation and masking}

Patients were allocated to treatment by central randomisation stratified by country according to a randomisation list generated by the interactive response technology provider. Patients, investigators, site staff and sponsor personnel were blinded to BDP/FF/G or BDP/FF 
1 assignment for the duration of the studies, with all patients using pressurised metered-dose

2 inhalers. Tiotropium (and BDP/FF in this arm) was administered open-label in TRIGGER.

\section{Procedures}

4 At each visit during the treatment period, data were collected for spirometry (pre-dose and

515 and 30 min, and 1, 2 and $3 \mathrm{~h}$ post-dose, with centralised spirometry) and ACQ-7. Asthma

6 exacerbations were captured throughout the study. Each day, pre-dose morning and

7 evening, patients recorded their peak expiratory flow (PEF), asthma symptoms (on a scale of

80 to 3 , where 0 was 'no symptoms'), and study treatment and rescue medication use in an

9 electronic diary.

10 Outcomes

11 The co-primary objectives were to demonstrate superiority of BDP/FF/G over BDP/FF in terms of pre-dose $\mathrm{FEV}_{1}$ at Week 26, and the rate of moderate to severe exacerbations over 52 weeks in each study. The key secondary objectives were to demonstrate superiority of $\mathrm{BDP} / \mathrm{FF} / \mathrm{G}$ over BDP/FF in terms of peak $\mathrm{FEV}_{1}$ at Week 26 and average morning PEF over the first 26 weeks of treatment in each study, and in terms of the rate of severe exacerbations using data pooled from the two studies.

17 Other secondary variables were: $\mathrm{FEV}_{1}$ peak and predose at all other visits, and $\mathrm{FEV}_{1}$ area under the curve (AUC) from 0 to $3 \mathrm{~h}$ post-dose, and ACQ-7 at all visits; FEV $\mathrm{F}_{1}$ response (change from baseline in pre-dose $\mathrm{FEV}_{1} \geq 100 \mathrm{~mL}$ ) and $\mathrm{ACQ}-7$ response (decrease from baseline score of at least 0.5 units) at Weeks 26 and 52; average morning and evening PEF over each inter-visit period and over 52 weeks, and average evening PEF over the first 26 weeks of treatment; time to first moderate and to first moderate or severe exacerbation; moderate exacerbation rate; and rescue use, rescue-free days, daily asthma symptoms, and asthma control days (days with a total asthma symptoms score of 0 and no rescue use) over each inter-visit period and over the first 26 and 52 weeks of treatment. Data were pooled from the two studies to compare BDP/FF/G with BDP/FF for the time to first moderate, 
1

severe, and moderate or severe exacerbation, and the rate of moderate and moderate and severe exacerbations. Severe exacerbations were prespecified to be analysed only in the pooled population as it was anticipated that the occurrence of these events would be relatively low.

A severe asthma exacerbation was defined as an asthma worsening requiring treatment with systemic corticosteroids for at least three days (with any associated emergency room visit or hospitalisation documented). Moderate exacerbations were defined in accordance with an American Thoracic Society/European Respiratory Society joint statement, ${ }^{12}$ as one or more of the following criteria:

- nocturnal awakening(s) due to asthma requiring short-acting $\beta_{2}$-agonist for two consecutive nights or increase $\geq 0.75$ from baseline in daily symptom score on two consecutive days;

- increase from baseline in short-acting $\beta_{2}$-agonist use on two consecutive days (minimum increase four puffs/day);

- $\quad \geq 20 \%$ decrease in PEF from baseline on at least two consecutive mornings/evenings or $\geq 20 \%$ decrease in $\mathrm{FEV}_{1}$ from baseline;

- visit to emergency room/study site for asthma treatment not requiring systemic corticosteroids.

Treatment-emergent adverse events (defined as events starting on or after first intake of randomised study medication) were captured throughout the study. Major adverse cardiovascular events were adjudicated by an independent committee, comprising three cardiologists.

\section{Statistical analysis}

To demonstrate superiority of BDP/FF/G over BDP/FF in terms of the co-primary and key secondary objectives in both studies, 574 patients needed to be randomised per treatment group. Since patients were randomised 2:2:1 in TRIGGER, 287 patients were needed for the 
1 BDP/FF + tiotropium group. This would give a total of 1148 patients in TRIMARAN and 1435

2 in TRIGGER. Further details on the sample size calculations are provided in the supplement.

3 In order to account for multiplicity, the comparisons between BDP/FF/G and BDP/FF in

4 terms of co-primary and key secondary efficacy endpoints were conducted according to the

5 following prespecified hierarchical testing procedure:

1. Pre-dose $\mathrm{FEV}_{1}$ at Week 26, and moderate and severe exacerbation rate over 52 weeks;

2. Peak FEV 1 at Week 26;

3. Average morning PEF over the first 26 weeks of treatment;

4. Severe exacerbation rate over 52 weeks in the pooled analysis.

At Step 1, superiority of BDP/FF/G over BDP/FF had to be demonstrated for both co-primary endpoints. At each of the next steps, confirmatory claims were to be made only when superiority had been demonstrated in all preceding steps. No multiplicity adjustments were applied to the other secondary endpoints, and so these $p$-values are descriptive, as are the comparisons between BDP/FF/G and BDP/FF + tiotropium.

Pre-dose and peak FEV 1 at Week 26 and average morning PEF over 26 weeks were analysed using a linear mixed model for repeated measures including treatment, visit, treatment by visit interaction and country as fixed effects, and baseline value and baseline by visit interaction as covariates (visit effect being replaced by inter-visit period effect for PEF), with data presented as adjusted means (i.e., least squares means), and adjusted mean differences between treatments with associated 95\% confidence intervals (Cls) and pvalues. An unstructured covariance matrix was assumed. The number of asthma exacerbations over the 52-week treatment period was analysed using a negative binomial model including treatment, country and number of exacerbations in the previous year (1 or $>1$ ) as fixed effects, and log-time on study as offset, and presented as adjusted asthma exacerbation rates, and adjusted rate ratios with $95 \% \mathrm{Cls}$ and $\mathrm{p}$-values. 
1 Most of the secondary efficacy endpoints were analysed using similar methods to the co-

2 primary and key secondary endpoints. $\mathrm{FEV}_{1}$ response and ACQ-7 response were compared

3 between treatment groups using a logistic model including treatment and country as factors

4 and the respective baseline values as a covariate. Time to first exacerbation were analysed

5 using a Cox proportional hazards model including treatment, country and number of

6 exacerbations in the previous year as factors. Estimation of the logistic and Cox proportional

7 hazards models was based on events per variable values well above the suggested

8 thresholds, confirming the reliability of the study results. ${ }^{13-15}$ All analyses reported in this

9 manuscript were prespecified.

10 All efficacy endpoints were analysed in the intention-to-treat population, defined as all

11 randomised patients who received at least one dose of the study treatment and with at least

12 one available evaluation of efficacy (primary or secondary efficacy variables) after baseline.

13 Safety data were analysed in the safety population, which comprised all randomised patients

14 who received at least one dose of study treatment. An independent Data Safety Monitoring

15 Board, composed of three independent clinicians and one independent biostatistician,

16 provided a quarterly independent scrutiny of the study. All analyses presented in this

17 manuscript were done with SAS software, version 9.4.

18 The studies are registered with ClinicalTrials.gov: TRIMARAN, NCT02676076; TRIGGER,

19 NCT02676089.

\section{Role of the funding source}

21 The funder of the study, Chiesi Farmaceutici SpA, was responsible for the design and

22 analysis of the studies, oversaw their conduct and was responsible for study report

23 preparation. All authors had full access to all data, with the lead author (JCV) responsible for

24 the decision to submit for publication. 


\section{Results}

2 TRIMARAN was conducted between February 2016 and May 2018 in 171 centres across

316 countries, whereas TRIGGER was conducted between April 2016 and May 2018 in 221

4 centres across 17 countries. The sites were a mixture of secondary and tertiary care centres

5 and specialised investigation units. Of the 1155 patients randomised into TRIMARAN, 94\%

6 completed treatment in both groups (Figure 1A), whereas of the 1437 patients in TRIGGER,

7 93\%, 93\% and 91\% completed treatment with BDP/FF/G, BDP/FF and BDP/FF + tiotropium,

8 respectively (Figure 1B). Baseline demographics were similar across the five groups (Table

9 1). Patients in TRIGGER had a slightly worse lung function (treatment group mean $51 \cdot 8-$

$1052 \cdot 1 \%$ predicted vs $55 \cdot 2-55 \cdot 7 \%)$ and higher reversibility $(33 \cdot 2-34 \cdot 9 \%$ vs $30 \cdot 8-32 \cdot 5 \%)$ than

11 those in TRIMARAN. 
Table 1. Baseline characteristics (safety population).

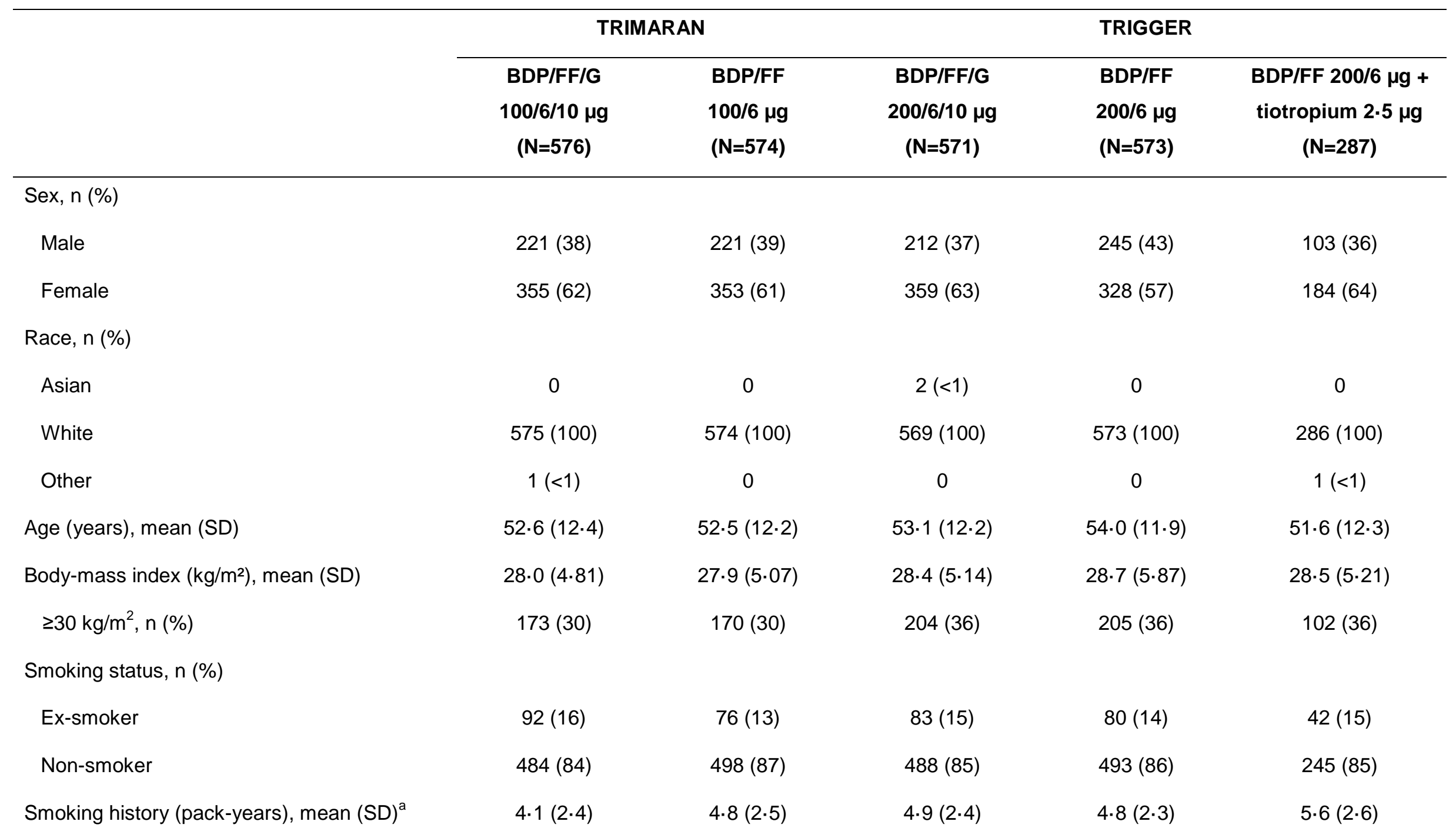




\begin{tabular}{|c|c|c|c|c|c|}
\hline & \multicolumn{2}{|c|}{ TRIMARAN } & \multicolumn{3}{|c|}{ TRIGGER } \\
\hline & $\begin{array}{c}B D P / F F / G \\
100 / 6 / 10 \mu g \\
(N=576)\end{array}$ & $\begin{array}{l}\text { BDP/FF } \\
100 / 6 \mu g \\
(N=574)\end{array}$ & $\begin{array}{c}\text { BDP/FF/G } \\
200 / 6 / 10 \mu g \\
(N=571)\end{array}$ & $\begin{array}{l}\text { BDP/FF } \\
200 / 6 \mu g \\
(N=573)\end{array}$ & $\begin{array}{l}\text { BDP/FF } 200 / 6 \mu \mathrm{g}+ \\
\text { tiotropium } 2.5 \mu \mathrm{g} \\
\quad(\mathrm{N}=287)\end{array}$ \\
\hline Duration of asthma (years), mean (SD) & $24.8(12.9)$ & $25 \cdot 2(12 \cdot 8)$ & $24 \cdot 8(12 \cdot 2)$ & $26 \cdot 2(12 \cdot 6)$ & $24 \cdot 5(12 \cdot 4)$ \\
\hline \multicolumn{6}{|l|}{ Exacerbations in the previous year, n (\%) } \\
\hline 1 & $474(82)$ & $473(82)$ & $439(77)$ & $452(79)$ & $229(80)$ \\
\hline$>1$ & $102(18)$ & $101(18)$ & $132(23)$ & $121(21)$ & $58(20)$ \\
\hline Pre-salbutamol FEV $1(\mathrm{~L})$, mean $(\mathrm{SD})^{\mathrm{b}}$ & $1 \cdot 7(0.56)$ & $1.7(0.56)$ & $1 \cdot 6(0.56)$ & $1.6(0.57)$ & $1.6(0.59)$ \\
\hline $\begin{array}{l}\text { Pre-salbutamol } \mathrm{FEV}_{1} \% \text { of predicted normal } \\
\text { value, mean }(\mathrm{SD})^{\mathrm{b}}\end{array}$ & \multicolumn{4}{|c|}{ value, mean $(S D)^{b}$} & $52 \cdot 1(13 \cdot 2)$ \\
\hline Range & 17 to 79 & 20 to 79 & 15 to 79 & 16 to 79 & 22 to 79 \\
\hline Reversibility (\%), mean (SD) & $32 \cdot 5(24 \cdot 72)$ & $30 \cdot 8(20 \cdot 53)$ & $33 \cdot 2(20 \cdot 21)$ & $33 \cdot 9(21 \cdot 87)$ & $34.9(26 \cdot 99)$ \\
\hline Range & $12 \cdot 1$ to $419 \cdot 2$ & $12 \cdot 1$ to $163 \cdot 0$ & $12 \cdot 1$ to $147 \cdot 9$ & $12 \cdot 0$ to $152 \cdot 5$ & $12 \cdot 2$ to $234 \cdot 5$ \\
\hline Pre-salbutamol FEV 1 /FVC, mean $(\mathrm{SD})^{\mathrm{b}}$ & $0.60(0.12)$ & $0.61(0.12)$ & $0.59(0.12)$ & $0.59(0.13)$ & $0.59(0.12)$ \\
\hline Range & 0.26 to 0.96 & 0.27 to 0.94 & 0.23 to 0.95 & 0.27 to 0.94 & 0.29 to 0.88 \\
\hline Post-salbutamol $\mathrm{FEV}_{1} / \mathrm{FVC}$, mean $(\mathrm{SD})^{\mathrm{c}}$ & $0.65(0.11)$ & $0.65(0.11)$ & $0.63(0.12)^{d}$ & $0 \cdot 63(0 \cdot 12)$ & $0.63(0.12)$ \\
\hline Range & 0.31 to 0.97 & 0.32 to 0.91 & 0.27 to 0.93 & 0.26 to 0.92 & 0.34 to 0.96 \\
\hline \multicolumn{6}{|l|}{ Prior inhaled corticosteroid and/or long-acting } \\
\hline$\beta_{2}$-agonist therapy, $n(\%)^{e}$ & & & & & \\
\hline
\end{tabular}




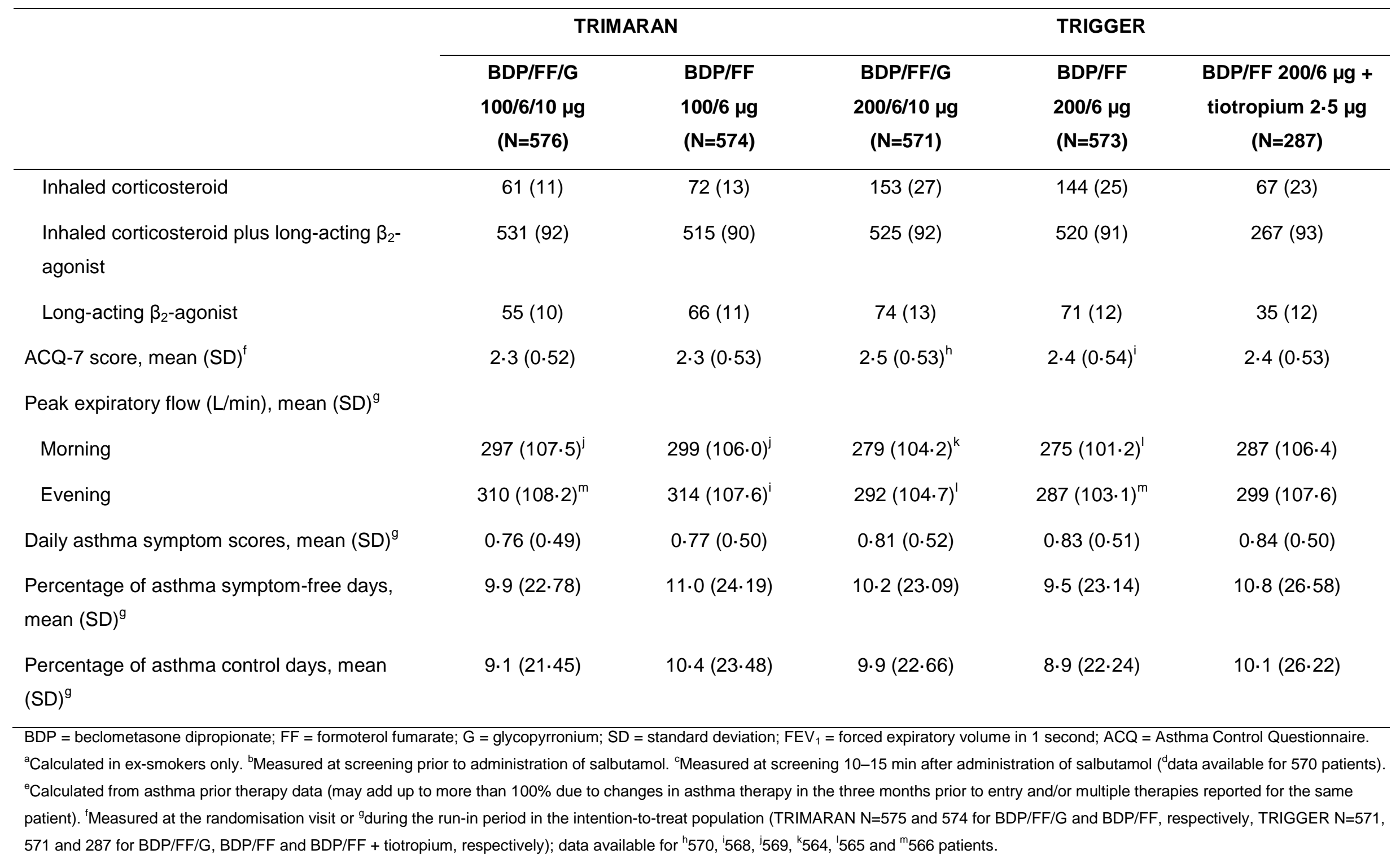


1 The co-primary endpoint of change in pre-dose FEV $\mathrm{F}_{1}$ at Week 26 was met in both studies,

2 with significant differences between BDP/FF/G and BDP/FF of $57 \mathrm{~mL}(95 \% \mathrm{Cl} 15-99$; $\mathrm{p}=0.0080)$ in TRIMARAN and $73 \mathrm{~mL}(26-120 ; \mathrm{p}=0.0025)$ in TRIGGER (Figure 2A, with absolute values in Supplementary Table 1). BDP/FF/G was not different from BDP/FF + tiotropium ( $-45 \mathrm{~mL}[-103$ to 13$] ; \mathrm{p}=0 \cdot 1253)$. BDP/FF/G reduced the rate of moderate and severe exacerbations by a significant $15 \%$ compared with BDP/FF in TRIMARAN (rate ratio 0.846 [0.725-0.987]; $p=0.0331 ;$ Figure 2B and Supplementary Table 1). The reduction in TRIGGER was $12 \%$, but it did not reach statistical significance $(0 \cdot 880$ [0.751-1.030]; $\mathrm{p}=0 \cdot 1102)$. No difference was observed between $\mathrm{BDP} / \mathrm{FF} / \mathrm{G}$ and BDP/FF + tiotropium (1.070 [0.878-1.303]; $p=0.5018)$. Since in TRIGGER statistical significance was not reached for this co-primary endpoint, in accordance with the prespecified hierarchical testing procedure, no formal claim of superiority can be made, either in this study or for the key secondary endpoint of severe exacerbation rate (pooled analysis). The corresponding p-values should therefore be interpreted descriptively.

For the key secondary endpoints of peak $\mathrm{FEV}_{1}$ at Week 26 and average morning PEF over 26 weeks, the change from baseline was higher with BDP/FF/G than BDP/FF in both studies $\left(p=0.0002\right.$ and $p<0.0001$ for peak $F E V_{1}$ and $p=0.0006$ and $p=0.0014$ for morning PEF in TRIMARAN and TRIGGER, respectively), with no differences between BDP/FF/G and $\mathrm{BDP} / \mathrm{FF}+$ tiotropium $(\mathrm{p}=0.2709$ and 0.9507 , respectively; Figure $3 \mathrm{~A}$ and $\mathrm{B}$, with absolute values in Supplementary Table 1). In the pooled analysis, BDP/FF/G reduced the rate of severe exacerbations vs BDP/FF by $23 \%$ ( $p=0.0076$; Figure 3C and Supplementary Table $1)$, and also reduced the rate of moderate exacerbations by $12 \%(p=0.0427)$ and of combined moderate and severe exacerbations by $14 \%(p=0.0083)$. In the individual studies, the same trend for a reduced rate with BDP/FF/G was observed for moderate exacerbations ( $p=0.0864$ and 0.2500 in TRIMARAN and TRIGGER, respectively; Supplementary Figure 1).

The time to first moderate or severe exacerbation was prolonged with BDP/FF/G compared with BDP/FF in both TRIMARAN (hazard ratio 0.842 [95\% CI 0.727-0.975]; $p=0.0217$ 
1 [Figure 4A]) and TRIGGER (0.799 [0.688-0.929]; $p=0.0035$ [Figure 4B]), and was similar for

$2 \mathrm{BDP} / \mathrm{FF} / \mathrm{G}$ and BDP/FF + tiotropium $(0.973$ [0.805-1.175]; $\mathrm{p}=0.7768)$. Likewise, the time to

3 first moderate exacerbation was prolonged with BDP/FF/G vs BDP/FF in both studies

4 (TRIMARAN 0.856 [0.733-0.999]; $p=0.0480 ;$ TRIGGER 0.808 [0.688-0.948]; $p=0.0089$ )

5 and was similar for BDP/FF/G and BDP/FF + tiotropium $(0.894$ [0.733-1.090]; $p=0.2663)$. In

6 the pooled analysis, BDP/FF/G prolonged the time to first moderate or severe $(0 \cdot 820$

$7 \quad[0.739-0.911] ; p=0.0002)$, moderate $(0.830[0.743-0.927] ; p=0.0010)$, and severe $(0.788$

$8[0.656-0.946] ; p=0.0106$ [Figure 4C]) exacerbation vs BDP/FF. Median times to event are in

9 Supplementary Table 2. In the pooled analyses, the numbers needed to treat for one year with BDP/FF/G rather than BDP/FF to prevent one exacerbation were three for moderate or severe exacerbations, 14 for severe exacerbations and five for moderate exacerbations.

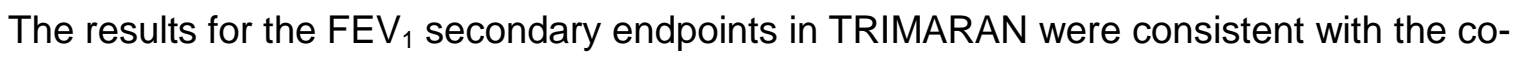
primary and key secondary $\mathrm{FEV}_{1}$ endpoints, with $\mathrm{BDP} / \mathrm{FF} / \mathrm{G}$ associated with improvements versus BDP/FF in pre-dose $\mathrm{FEV}_{1}$ at most visits (Supplementary Figure 2), peak $F E V_{1}$ and $\mathrm{FEV}_{1} \mathrm{AUC}_{0-3 \mathrm{~h}}$ at all visits (Supplementary Figures 3 and 4), and $\mathrm{FEV}_{1}$ response at Week 26 (Supplementary Table 3). In TRIGGER, BDP/FF/G improved peak FEV , $_{1}$, pre-dose FEV ${ }_{1}$, and $\mathrm{FEV}_{1} \mathrm{AUC}_{0-3 \mathrm{~h}}$ versus $\mathrm{BDP} / \mathrm{FF}$ at all visits, and $\mathrm{FEV}_{1}$ response at Weeks 26 and 52, with no differences between BDP/FF/G and BDP/FF + tiotropium.

BDP/FF/G improved all PEF-based secondary endpoints compared with BDP/FF in both studies (Supplementary Figures 5-7). There were no clinically relevant differences between $\mathrm{BDP} / \mathrm{FF} / \mathrm{G}$ and $\mathrm{BDP} / \mathrm{FF}$ or BDP/FF + tiotropium in terms of $\mathrm{ACQ}-7$ total score or responders (Supplementary Figure 8 and Supplementary Table 3), or in the rescue medication use endpoints (Supplementary Figure 9 and 10, and Supplementary Table 3). Notably, there was an improvement from baseline in asthma symptoms, control and rescue medication use in all five groups over the duration of the studies, with an improvement in TRIGGER for BDP/FF/G vs BDP/FF in terms of asthma symptom-free days and asthma control days from Week 13 onwards (Supplementary Figures 11-13, and Supplementary Table 3). 
1 Overall, a similar proportion of patients had adverse events in all five groups (Table 2). The

2 majority of events were mild or moderate in severity, and few were considered related to

3 treatment. The most common adverse event in all groups was asthma exacerbation, the

4 occurrence of which was lower with triple therapy than with BDP/FF. Four patients

5 experienced treatment-related serious adverse events: atrial fibrillation, in a patient receiving

6 BDP/FF/G 100/6/10 $\mu \mathrm{g}$, and who had hypertension; oesophageal candidiasis in a patient

7 receiving BDP/FF/G 200/6/10 $\mu$ g that resolved after therapy; and pneumonia, which resolved

8 after therapy, and angle closure glaucoma, which had not resolved by the end of the study in

9 patients receiving BDP/FF 200/6 $\mu \mathrm{g}$. All were moderate in severity, and did not require a

10 change in study treatment. Five patients in TRIMARAN experienced major adverse

11 cardiovascular events, as did six patients in TRIGGER, although none of the events in either

12 study were considered related to study treatment (Table 2 and Supplementary Table 4).

13 Three patients in the BDP/FF/G group in TRIMARAN experienced adverse events leading to

14 death (one patient with left ventricular failure, one with acute pancreatitis, and one patient

15 with gastric cancer and acute cardiac failure). In TRIGGER, two patients experienced an

16 adverse event leading to death, one in the BDP/FF/G group (cerebral haemorrhage) and one

17 in the BDP/FF group (sudden death). None of the deaths in either study was considered

18 related to study treatment.

19 Table 2. Treatment-emergent adverse events and serious adverse events (safety 20 population).

\begin{tabular}{|c|c|c|c|c|c|}
\hline \multirow[b]{2}{*}{$\begin{array}{l}\text { Number (\%) of } \\
\text { patients }\end{array}$} & \multicolumn{2}{|c|}{ TRIMARAN } & \multicolumn{3}{|c|}{ TRIGGER } \\
\hline & $\begin{array}{c}B D P / F F / G \\
100 / 6 / 10 \mu g \\
(N=576)\end{array}$ & $\begin{array}{l}\text { BDP/FF } \\
100 / 6 \mu g \\
(N=574)\end{array}$ & $\begin{array}{c}B D P / F F / G \\
200 / 6 / 10 \mu g \\
(N=571)\end{array}$ & $\begin{array}{l}\text { BDP/FF } \\
200 / 6 \mu g \\
(N=573)\end{array}$ & $\begin{array}{c}\text { BDP/FF } 200 / 6 \mu \mathrm{g}+ \\
\text { tiotropium } 2.5 \mu \mathrm{g} \\
(\mathrm{N}=287)\end{array}$ \\
\hline Adverse events & $431(75)$ & $455(79)$ & $410(72)$ & $443(77)$ & $210(73)$ \\
\hline $\begin{array}{l}\text { Asthma } \\
\text { exacerbation }\end{array}$ & 337 (59) & $379(66)$ & $323(57)$ & $364(64)$ & $162(56)$ \\
\hline Nasopharyngitis & $71(12)$ & $79(14)$ & $46(8)$ & $63(11)$ & $34(12)$ \\
\hline Headache & $38(7)$ & $46(8)$ & $25(4)$ & $27(5)$ & $13(5)$ \\
\hline
\end{tabular}




\begin{tabular}{|c|c|c|c|c|c|}
\hline \multirow[b]{2}{*}{$\begin{array}{l}\text { Number (\%) of } \\
\text { patients }\end{array}$} & \multicolumn{2}{|c|}{ TRIMARAN } & \multicolumn{3}{|c|}{ TRIGGER } \\
\hline & $\begin{array}{c}B D P / F F / G \\
100 / 6 / 10 \mu g \\
(N=576)\end{array}$ & $\begin{array}{l}B D P / F F \\
100 / 6 \mu g \\
(N=574)\end{array}$ & $\begin{array}{c}B D P / F F / G \\
200 / 6 / 10 \mu g \\
(N=571)\end{array}$ & $\begin{array}{l}\text { BDP/FF } \\
200 / 6 \mu g \\
(N=573)\end{array}$ & $\begin{array}{c}\text { BDP/FF } 200 / 6 \mu \mathrm{g}+ \\
\text { tiotropium } 2.5 \mu \mathrm{g} \\
\quad(\mathrm{N}=287)\end{array}$ \\
\hline $\begin{array}{l}\text { Respiratory tract } \\
\text { infection viral }\end{array}$ & $15(3)$ & $26(5)$ & $17(3)$ & $28(5)$ & $14(5)$ \\
\hline Bronchitis & $18(3)$ & $22(4)$ & $18(3)$ & $18(3)$ & $12(4)$ \\
\hline Pharyngitis & $12(2)$ & $16(3)$ & $10(2)$ & $12(2)$ & $4(1)$ \\
\hline $\begin{array}{l}\text { Viral upper } \\
\text { respiratory tract } \\
\text { infection }\end{array}$ & $12(2)$ & $16(3)$ & $4(1)$ & $8(1)$ & $3(1)$ \\
\hline Hypertension & $16(3)$ & $9(2)$ & $10(2)$ & $7(1)$ & $7(2)$ \\
\hline $\begin{array}{l}\text { Upper respiratory } \\
\text { tract infection }\end{array}$ & $11(2)$ & $10(2)$ & $9(2)$ & $15(3)$ & $7(2)$ \\
\hline $\begin{array}{l}\text { Treatment-related } \\
\text { adverse events }\end{array}$ & $22(4)$ & $19(3)$ & $28(5)$ & $24(4)$ & $16(6)$ \\
\hline Dysphonia & $9(2)$ & $1(<1)$ & $10(2)$ & $8(1)$ & $2(1)$ \\
\hline Cough & $1(<1)$ & 0 & 0 & $1(<1)$ & $2(1)$ \\
\hline Oral candidiasis & $1(<1)$ & $4(1)$ & $3(1)$ & $3(1)$ & $3(1)$ \\
\hline Dry mouth & $4(1)$ & 0 & $3(1)$ & $1(<1)$ & $2(1)$ \\
\hline $\begin{array}{l}\text { Electrocardiogram } \\
\text { QT prolonged }\end{array}$ & $1(<1)$ & $3(1)$ & $1(<1)$ & $1(<1)$ & 0 \\
\hline Muscle spasms & 0 & 0 & $3(1)$ & $3(1)$ & 0 \\
\hline $\begin{array}{l}\text { Serious adverse } \\
\text { events }\end{array}$ & $28(5)$ & $22(4)$ & $28(5)$ & $33(6)$ & $15(5)$ \\
\hline $\begin{array}{l}\text { Asthma } \\
\text { exacerbation }\end{array}$ & $7(1)$ & $4(1)$ & $11(2)$ & $11(2)$ & $6(2)$ \\
\hline Pneumonia & 0 & $3(1)$ & $3(1)$ & $5(1)$ & $2(1)$ \\
\hline $\begin{array}{l}\text { Treatment-related } \\
\text { serious adverse } \\
\text { events }\end{array}$ & $1(<1)$ & 0 & $1(<1)$ & $2(<1)$ & 0 \\
\hline $\begin{array}{l}\text { Severe adverse } \\
\text { events }\end{array}$ & $34(6)$ & $38(7)$ & $35(6)$ & $55(10)$ & $13(5)$ \\
\hline
\end{tabular}




\begin{tabular}{|c|c|c|c|c|c|}
\hline \multirow[b]{2}{*}{$\begin{array}{l}\text { Number (\%) of } \\
\text { patients }\end{array}$} & \multicolumn{2}{|c|}{ TRIMARAN } & \multicolumn{3}{|c|}{ TRIGGER } \\
\hline & $\begin{array}{c}\text { BDP/FF/G } \\
100 / 6 / 10 \mu g \\
(N=576)\end{array}$ & $\begin{array}{c}\text { BDP/FF } \\
100 / 6 \mu g \\
(\mathrm{~N}=574)\end{array}$ & $\begin{array}{c}B D P / F F / G \\
200 / 6 / 10 \mu g \\
(N=571)\end{array}$ & $\begin{array}{l}\text { BDP/FF } \\
200 / 6 \mu g \\
(N=573)\end{array}$ & $\begin{array}{c}\mathrm{BDP} / \mathrm{FF} 200 / 6 \mu \mathrm{g}+ \\
\text { tiotropium } 2.5 \mu \mathrm{g} \\
(\mathrm{N}=287)\end{array}$ \\
\hline $\begin{array}{l}\text { Major adverse } \\
\text { cardiovascular } \\
\text { events }\end{array}$ & $4(1)$ & $1(<1)$ & $3(1)$ & $3(1)$ & 0 \\
\hline $\begin{array}{l}\text { Adverse events } \\
\text { leading to study drug } \\
\text { discontinuation }\end{array}$ & $4(1)$ & $5(1)$ & $4(1)$ & $8(1)$ & $2(1)$ \\
\hline $\begin{array}{l}\text { Adverse events } \\
\text { leading to death }\end{array}$ & $3(1)$ & 0 & $1(<1)$ & $1(<1)$ & 0 \\
\hline
\end{tabular}




\section{Discussion}

2 TRIMARAN and TRIGGER are the first studies to evaluate the efficacy and safety of single-

3 inhaler triple therapy in the management of asthma. The lung function (pre-dose $\mathrm{FEV}_{1}$ ) co-

4 primary endpoint was met in both studies, with a slightly larger effect size in TRIGGER.

5 Furthermore, the moderate and severe exacerbations co-primary endpoint was met in

6 TRIMARAN, with a significant $15 \%$ reduction for BDP/FF/G vs BDP/FF; although there was

7 similar effect size in TRIGGER, with a $12 \%$ reduction, statistical significance was not

8 achieved. In the prespecified analysis of data pooled from the two studies, BDP/FF/G

9 reduced the rate of the more clinically-relevant severe exacerbations by $23 \%$. Furthermore,

10 for the secondary exacerbations endpoints, in the pooled analyses BDP/FF/G reduced the

11 rate of moderate and combined moderate and severe exacerbations by 12 and $14 \%$,

12 respectively, and prolonged the time to first moderate or severe, moderate, and severe exacerbation compared with BDP/FF. The totality of the exacerbations data therefore suggest that BDP/FF/G prevents these events to a greater degree than BDP/FF.

Although care should be taken comparing studies, the $23 \%$ reduction in the rate of severe exacerbations along with the $21 \%$ risk reduction (hazard ratio 0.79 for time to first severe exacerbation) are consistent with the results of two long-term studies in which tiotropium was added as a free combination to any inhaled corticosteroid and long-acting $\beta_{2}$-agonist (where there was a $20 \%$ rate reduction and a $21 \%$ risk reduction for tiotropium vs placebo). ${ }^{3}$ Importantly, however, TRIMARAN and TRIGGER had less strict exclusion criteria than these studies and so enrolled broader patient populations. Specifically, the tiotropium studies were limited to a subgroup of patients with post-bronchodilator $\mathrm{FEV}_{1} \leq 80 \%$ and $\mathrm{FEV}_{1}$ to forced vital capacity (FVC) ratio $\leq 70 \%,{ }^{3}$ compared with pre-bronchodilator $\mathrm{FEV}_{1}<80 \%$ in TRIMARAN and TRIGGER and no limitation on the $\mathrm{FEV}_{1} / \mathrm{FVC}$ ratio. Another key difference is that the earlier studies administered triple therapy via multiple inhalers, and did not supply or monitor the daily concomitant use of inhaled corticosteroid/long-acting $\beta_{2}$-agonist. The use of single-inhaler triple therapy in TRIMARAN and TRIGGER ensured the delivery of all three 
components and should potentially optimise treatment adherence and persistence. We acknowledge, however, that in TRIGGER for $\mathrm{FEV}_{1}$ and moderate-to-severe exacerbations, BDP/FF + tiotropium (administered open-label via separate inhalers) exhibited numerically greater improvements vs BDP/FF (although not statistically significant) than single inhaler (and double-blind) BDP/FF/G.

The majority of exacerbations in TRIMARAN and TRIGGER were moderate in severity, which by definition were predominantly self-managed by patients. To our knowledge, this is the first study to evaluate the effect of inhaled therapy on such exacerbations by applying the American Thoracic Society/European Respiratory Society joint statement definition. ${ }^{12}$ Although there was a consistent trend in favour of triple therapy, there was no significant treatment effect for the rate of moderate exacerbations in the individual studies, yet the time to first moderate exacerbation was extended with BDP/FF/G vs BDP/FF, both in the pooled analysis and in each individual study. The reasons for this are unclear - although it may be associated with the variability of symptoms in asthma (the worsening of which defines a moderate exacerbation episode), so making it challenging to assess this outcome precisely. In addition, neither study was powered to evaluate the effect of treatment on moderate exacerbations. The effect of triple therapy on the objective lung function endpoints, $\mathrm{FEV}_{1}$ and PEF, was consistent, within and between studies, with both BDP/FF/G doses improving these endpoints vs BDP/FF for the duration of the studies.

Asthma control, symptom endpoints and rescue medication use improved from baseline with all treatments. Interestingly, in TRIMARAN BDP/FF/G and BDP/FF resulted in similar improvements in symptom-free days and asthma control days, whereas in TRIGGER there was a separation between BDP/FF/G and BDP/FF, particularly over the second half of the study. These results are similar to those of the previous tiotropium studies, in which tiotropium administered separately to inhaled corticosteroid plus a long-acting $\beta_{2}$-agonist resulted in consistent improvements in lung function, but less consistent improvements in ACQ-7 score, ${ }^{3,4}$ and with a dissociation in effect between severe exacerbations and asthma 
1 control. ${ }^{3}$ For the populations that we recruited (who had uncontrolled disease despite

2 medium or high-dose inhaled corticosteroid plus a long-acting $\beta_{2}$-agonist), the prevention of

3 future exacerbations (especially severe exacerbations) is arguably the more important

4 treatment goal.

5 We acknowledge that the improvement in asthma control and decrease in symptoms in all

6 groups, including in those patients who continued BDP/FF therapy from the run-in period

7 across the 52-week trial duration, suggests a clinical trial effect in both studies, which can

8 arise at least in part due to improved adherence. This clinical trial effect also appeared to

9 impact severe exacerbations, with a low rate observed during the trial $(0.310$ in the pooled

$10 \mathrm{BDP} / \mathrm{FF}$ group), despite all patients being required to have a history of at least one exacerbation requiring treatment with systemic corticosteroids or emergency department visit or in-patient hospitalisation. In this context, the much lower rate of severe exacerbations observed during the studies compared to the historic data is similar to a number of clinical trials that recruited similar populations, ${ }^{16-20}$ potentially also reflecting increased adherence to therapy or improved care as a result of clinical trial participation. Importantly, when the study was designed, it was anticipated that the rate of these more clinically relevant exacerbations would be lower than that of moderate exacerbations - which is why the only prespecified analysis of severe exacerbation rate was in the pooled population. It is notable, therefore, that despite this low rate, there was still a $23 \%$ reduction with BDP/FF/G vs BDP/FF.

It is always challenging to interpret the clinical relevance of results when evaluating the additive effect of a therapy on top of therapies that are known to be effective. It could be argued that the differences that we observed between BDP/FF/G and BDP/FF for some of the endpoints were numerically small (with the differences in pre-dose FEV ${ }_{1}$ at Week 26 and in morning PEF over 26 weeks lower than those included in the powering assumptions), and indicate only a modest effect of triple therapy. However, the populations that we studied (adults with uncontrolled asthma despite receiving a long-acting $\beta_{2}$-agonist plus either a medium- or high-dose inhaled corticosteroid) have limited treatment options available, and 
1

so even modest incremental improvements can be valuable. Uncontrolled asthma is associated with a substantial (and growing) economic and health burden, ${ }^{21}$ especially due to exacerbations, and so additional therapies are needed. In this context, a key finding is that all treatments were similarly well tolerated. This is again consistent with the results of a number of other triple therapy studies in asthma, in which the addition of long-acting muscarinic antagonist did not impact the overall adverse event profile. ${ }^{3-5,22}$

Given the broad inclusion criteria of these two studies, the results should be generalisable to adults with asthma that is uncontrolled by an inhaled corticosteroid plus a long-acting $\beta_{2^{-}}$ agonist (although we recognise that the recruited populations were predominantly of white race). The Global Initiative for Asthma (GINA) report already includes recommendations for add-on long-acting muscarinic antagonist use for patients whose asthma is not well controlled on inhaled corticosteroid plus long-acting $\beta_{2}$-agonist therapy. ${ }^{1}$ For such patients, escalation of therapy to inhaled triple therapy has been shown to be cost-effective compared to an inhaled corticosteroid plus a long-acting $\beta_{2}$-agonist, ${ }^{23-27}$ and is likely to be cost-effective compared to the addition of systemic biological therapy. ${ }^{25}$ Since BDP/FF/G delivers the three molecules via one device, and based on the magnitude of reduction in the annual rate of severe asthma exacerbations observed in the prespecified pooled analysis of TRIMARAN and TRIGGER, it is expected that BDP/FF/G will provide an attractive treatment option, fulfilling a significant unmet need at both the individual patient and the overall health system levels.

In conclusion, taken together these data indicate that in adults with uncontrolled asthma treated with a medium-to-high dose inhaled corticosteroid plus a long-acting $\beta_{2}$-agonist the addition of a long-acting muscarinic antagonist in a single inhaler BDP/FF/G triple therapy mainly improves lung function with an associated positive impact on severe exacerbations, and a less marked benefit in terms of asthma symptoms or control. 


\section{Contributors}

2 The studies were conceived and designed by JCV, AP, MK, SP and GWC. The data were

3 acquired by JCV, PK, PP and GWC, analysed by AV, and interpreted by JCV, PK, PP, AP,

4 DS, SC, FZ, AV, MK, GG, SP and GWC. MK and GG contributed to the medical data

5 integrity. SC and FZ contributed to the conduct of the studies. SC and FZ were Chiesi

6 clinical operation project managers, AV was Chiesi statistician, SP was Head of Chiesi

7 global clinical development, and GG was the Clinical Program Leader. JCV and GWC were

8 principal investigators of TRIMARAN and TRIGGER, respectively. The manuscript was

9 revised for intellectual content and approved for publication by JCV, PK, PP, AP, DS, SC,

$10 \mathrm{FZ}, \mathrm{AV}, \mathrm{MK}, \mathrm{GG}, \mathrm{SP}$ and GWC.

\section{Declaration of interests}

JCV reports personal fees from Chiesi during the conduct of the study. In the past JCV has lectured and received honoraria from AstraZeneca, Avontec, Bayer, Bencard, Bionorica, Boehringer-Ingelheim, Chiesi, Essex/Schering-Plough, GSK, Janssen-Cilag, Leti, MEDA, Merck, MSD, Mundipharma, Novartis, Nycomed/Altana, Pfizer, Revotar, Sanofi/Regeneron, Sandoz-Hexal, Stallergens, TEVA, UCB/Schwarz-Pharma, Zydus/Cadila and possibly others, and participated in advisory boards and received honoraria from Avontec, Boehringer-Ingelheim, Chiesi, Essex/Schering-Plough, GSK, Janssen-Cilag, MEDA, MSD, Mundipharma, Novartis, Paul-Ehrlich Institut, Regeneron, Revotar, Roche, Sanofi-Aventis, Sanofi/Regeneron, Sandoz-Hexal, TEVA, UCB/Schwarz-Pharma and possibly others, and received funding for research from Deutsche Forschungsgesellschaft, Land MecklenburgVorpommern, GSK, and MSD, and has advised the Bemeinsame Bundesausschuss (GBA). PK reports personal fees from Chiesi, Novartis, AstraZeneca, Boehringer Ingelheim, Berlin Chemie Menarini, Adamed, Polpharma and Lekam, all outside the submitted work. PP reports grants and personal fees from AstraZeneca and Chiesi, and personal fees from GSK, Menarini, Mundipharma, Novartis and Sanofi, all outside the submitted work. 
1 AP reports grants, personal fees, non-financial support and payment for advisory board

2 membership, consultancy, payment for lectures, grants for research, and travel expenses

3 reimbursement from Chiesi, Astrazeneca, GlaxoSmithKline, Boehringer Ingelheim,

4 Mundipharma and TEVA, and personal fees and non-financial support from Menarini,

5 Novartis, Zambon and Sanofi, all outside the submitted work.

6 DS reports personal fees from Chiesi during the conduct of the study. Outside the submitted

7 work, he reports personal fees from AstraZeneca, Boehringer Ingelheim, Chiesi, Cipla,

8 Genentech, GlaxoSmithKline, Glenmark, Menarini, Mundipharma, Novartis, Peptinnovate,

9 Pfizer, Pulmatrix, Therevance, and Verona.

10 SC, FZ, AV, MK and SP are employees of Chiesi, the sponsor of the studies.

$11 \mathrm{GG}$ is an employee of Chiesi USA, Inc.

12 GWC reports personal fees from A. Menarini, Alk-Abello, Allergy Therapeutics, AstraZeneca-

13 Medimmune, Boehringer Ingelheim, Chiesi Farmaceutici, Genentech, Guidotti-Malesci,

14 Glaxo Smith Kline, Hal Allergy, Merck Sharp \& Dome, Mundipharma, Novartis, Orion,

15 Sanofi-Aventis, Sanofi Genzyme/Regeneron, Stallergenes-Greer, Uriach Pharma, Teva,

16 Valeas, ViforPharma, all outside the submitted work.

\section{Acknowledgements}

18 Dave Singh is supported by the National Institute for Health Research (NIHR) Manchester

19 Biomedical Research Centre (BRC).

These studies were funded by Chiesi Farmaceutici SpA. We thank the investigators and patients at the investigative sites for their support of these studies. Writing support was provided by David Young of Young Medical Communications and Consulting Ltd, funded by Chiesi Farmaceutici SpA. 


\section{Data sharing}

2 Chiesi commits to sharing with qualified scientific and medical researchers, conducting

3 legitimate research, the anonymised patient-level and study-level data, the clinical protocol

4 and the full clinical study report of Chiesi Farmaceutici SpA-sponsored interventional clinical

5 trials in patients for medicines and indications approved by the European Medicines Agency

6 and/or the US Food and Drug Administration after $1^{\text {st }}$ January 2015, following the approval of

7 any received research proposal and the signature of a Data Sharing Agreement. Chiesi

8 provides access to clinical trial information consistently with the principle of safeguarding

9 commercially confidential information and patient privacy. Other information on Chiesi's data

10 sharing commitment, access and research request's approval process are available in the

11 Clinical Trial Transparency section of http://www.chiesi.com/en/research-and-development/. 


\section{References}

1 Reddel HK, FitzGerald JM, Bateman ED, et al. GINA 2019: a fundamental change in asthma management: Treatment of asthma with short-acting bronchodilators alone is no longer recommended for adults and adolescents. Eur Respir J 2019; 53: 1901046.

2 Hirst C, Calingaert B, Stanford R, Castellsague J. Use of long-acting $\beta$-agonists and inhaled steroids in asthma: Meta-analysis of observational studies. J Asthma 2010; 47: 439-46.

3 Kerstjens HAM, Engel M, Dahl R, et al. Tiotropium in asthma poorly controlled with standard combination therapy. N Engl J Med 2012; 367: 1198-207.

4 Ohta K, Ichinose M, Tohda $Y$, et al. Long-term once-daily tiotropium Respimat $\AA$ is well tolerated and maintains efficacy over 52 weeks in patients with symptomatic asthma in Japan: A randomised, placebo-controlled study. PLoS One 2015; 10: e0124109.

$5 \quad$ Hoshino M, Ohtawa J, Akitsu K. Effects of the addition of tiotropium on airway dimensions in symptomatic asthma. Allergy Asthma Proc 2016; 37: 147-53.

6 Delea TE, Hagiwara M, Stanford R, Stempel D. Effects of fluticasone propionate/salmeterol combination on asthma-related health care resource utilization and costs and adherence in children and adults with asthma. Clin Ther 2008; 30: 560-71.

7 Marceau C, Lemière C, Berbiche D, Perreault S, Blais L. Persistence, adherence, and effectiveness of combination therapy among adult patients with asthma. J Allergy Clin Immunol 2006; 118: 574-81.

8 Stoloff SW, Stempel DA, Meyer J, Stanford RH, Carranza Rosenzweig JR. Improved refill persistence with fluticasone propionate and salmeterol in a single inhaler compared with other controller therapies. J Allergy Clin Immunol 2004; 113: 245-51.

9 Stempel DA, Stoloff SW, Carranza Rosenzweig JR, Stanford RH, Ryskina KL, Legorreta AP. Adherence to asthma controller medication regimens. Respir Med 2005; 99: 1263-7.

10 Lipworth B, Manoharan A, Anderson W. Unlocking the quiet zone: the small airway asthma phenotype. Lancet Respir Med 2014; 2: 497-506.

11 Postma DS, Brightling C, Baldi S, et al. Exploring the relevance and extent of small airways dysfunction in asthma (ATLANTIS): baseline data from a prospective cohort study. Lancet Respir Med 2019; 7: 402-16.

12 Virchow JC, Backer V, de Blay F, et al. Defining moderate asthma exacerbations in clinical trials based on ATS/ERS joint statement. Respir Med 2015; 109: 547-56.

13 Peduzzi P, Concato J, Kemper E, Holford TR, Feinstein AR. A simulation study of the number of events per variable in logistic regression analysis. J Clin Epidemiol 1996; 49: 1373-9.

14 Concato J, Peduzzi P, Holford TR, Feinstein AR. Importance of events per independent variable in proportional hazards analysis I. Background, goals, and general strategy. J Clin Epidemiol 1995; 48: 1495-501.

15 Peduzzi P, Concato J, Feinstein AR, Holford TR. Importance of events per independent variable in proportional hazards regression analysis. II. Accuracy and precision of regression estimates. J Clin Epidemiol 1995; 48: 1503-10.

16 Ortega HG, Liu MC, Pavord ID, et al. Mepolizumab treatment in patients with severe eosinophilic asthma. N Engl J Med 2014; 371: 1198-207. 
17 Chupp GL, Bradford ES, Albers FC, et al. Efficacy of mepolizumab add-on therapy on health-related quality of life and markers of asthma control in severe eosinophilic asthma (MUSCA): a randomised, double-blind, placebo-controlled, parallel-group, multicentre, phase 3b trial. Lancet Respir Med 2017; 5: 390-400.

18 Bleecker ER, FitzGerald JM, Chanez P, et al. Efficacy and safety of benralizumab for patients with severe asthma uncontrolled with high-dosage inhaled corticosteroids and long-acting beta2-agonists (SIROCCO): a randomised, multicentre, placebocontrolled phase 3 trial. Lancet 2016; 388: 2115-27.

19 FitzGerald JM, Bleecker ER, Nair P, et al. Benralizumab, an anti-interleukin-5 receptor a monoclonal antibody, as add-on treatment for patients with severe, uncontrolled, eosinophilic asthma (CALIMA): a randomised, double-blind, placebo-controlled phase 3 trial. Lancet 2016; 388: 2128-41.

20 Castro M, Corren J, Pavord ID, et al. Dupilumab efficacy and safety in moderate-tosevere uncontrolled asthma. N Engl J Med 2018; 378: 2486-96.

21 Yaghoubi M, Adibi A, Safari A, FitzGerald JM, Sadatsafavi M. The projected economic and health burden of uncontrolled asthma in the United States. Am J Respir Crit Care Med 2019; published online June 5. DOI:10.1164/rccm.201901-0016OC.

22 Dahl R, Engel M, Dusser D, et al. Safety and tolerability of once-daily tiotropium Respimat ${ }^{\circledR}$ as add-on to at least inhaled corticosteroids in adult patients with symptomatic asthma: A pooled safety analysis. Respir Med 2016; 118: 102-11.

23 Echave M, Ojanguren M, Elias I, et al. Cost-effectiveness of tiotropium in the treatment of patients with asthma. Value Health 2015; 18: A501.

24 Willson J, Bateman ED, Pavord I, Lloyd A, Krivasi T, Esser D. Cost effectiveness of tiotropium in patients with asthma poorly controlled on inhaled glucocorticosteroids and long-acting $\beta$-agonists. Appl Health Econ Health Policy 2014; 12: 447-59.

25 Zafari Z, Sadatsafavi M, Mark FitzGerald J, Canadian Respiratory Research Network. Cost-effectiveness of tiotropium versus omalizumab for uncontrolled allergic asthma in US. Cost Eff Resour Alloc 2018; 16: 3.

26 Pawlik M, Walczak J, Pieniazek I. Economic evaluation of tiotropium administrated through the Respimat inhaler as add-on therapy in patients with uncontrolled severe asthma in Poland. Value Health 2015; 18: A502.

27 Silva Miguel L, Manacas M, Pinheiro B. Economic evaluation of tiotropium for severe persistent asthma in Portugal. Value Health 2015; 18: A502. 


\section{Figure legends}

2 Figure 1. Patient disposition in A) TRIMARAN and B) TRIGGER.

$3 \mathrm{BDP}=$ beclometasone dipropionate; $\mathrm{FF}=$ formoterol fumarate; $\mathrm{G}=$ glycopyrronium

4 Figure 2. Co-primary endpoints: A) Pre-dose FEV 1 change from baseline at Week 26 and B)

5 annualised moderate and severe exacerbation rate (intention-to-treat population).

6 Panel A: Data are adjusted means and adjusted mean differences (95\% confidence interval). Panel B: Data are adjusted

7 exacerbation rates per patient per year and adjusted rate ratios ( $95 \%$ confidence interval). BDP = beclometasone dipropionate;

$8 \mathrm{FF}=$ formoterol fumarate; $\mathrm{G}=$ glycopyrronium; $\mathrm{FEV}_{1}=$ forced expiratory volume in 1 second.

9 Figure 3. Key secondary endpoints: A) Peak FEV change from baseline at Week 26

10 (intention-to-treat population), B) average morning PEF change from baseline over 26 weeks

11 (intention-to-treat population), and C) annualised severe, moderate, and moderate and severe exacerbation rate (pooled analysis, intention-to-treat population).

13 Panels A and B: Data are adjusted means and adjusted mean differences (95\% confidence interval). Panel C: Data are

14 adjusted exacerbation rates per patient per year and adjusted rate ratios (95\% confidence interval). BDP = beclometasone dipropionate; FF = formoterol fumarate; $G$ = glycopyrronium; $F E V_{1}=$ forced expiratory volume in 1 second; $P E F=$ peak expiratory flow.

17 Figure 4. Time to first moderate or severe exacerbation in A) TRIMARAN and B) TRIGGER (intention-to-treat populations), and C) pooled analysis of time to first severe exacerbation. $\mathrm{BDP}=$ beclometasone dipropionate; $\mathrm{FF}=$ formoterol fumarate; $\mathrm{G}=$ glycopyrronium; $\mathrm{HR}=$ hazard ratio; $\mathrm{Cl}=$ confidence interval. 


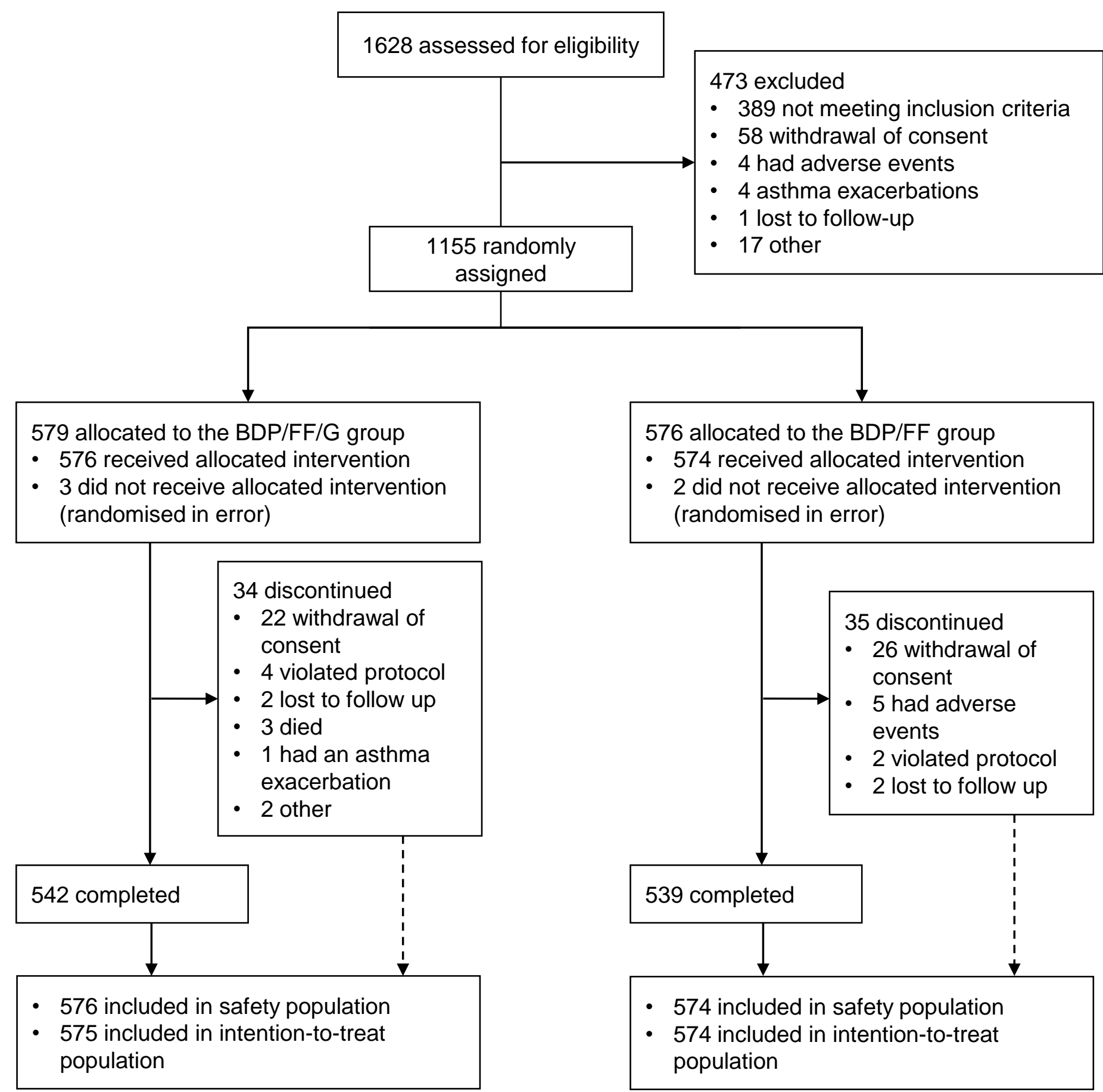




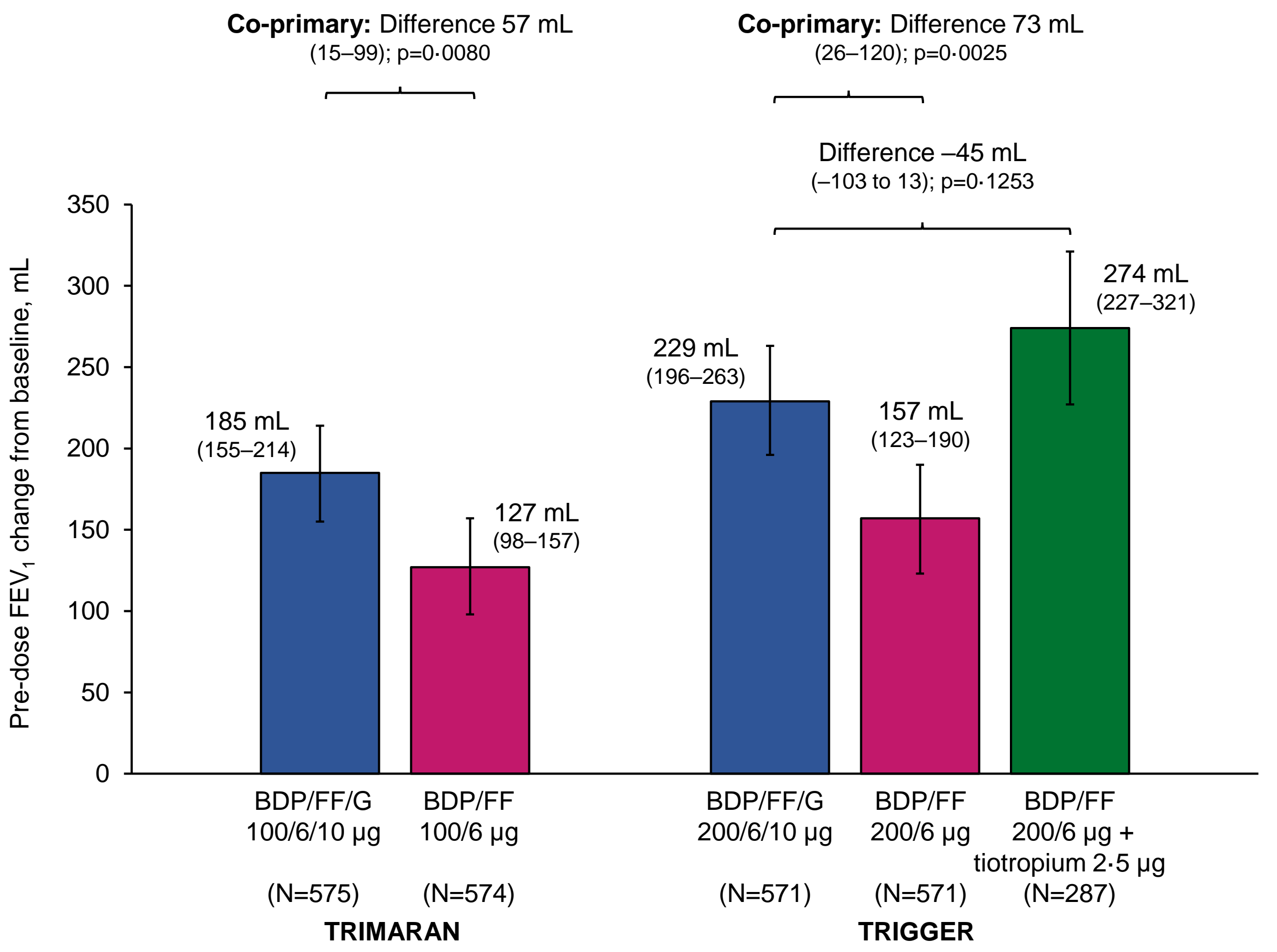


Co-primary: Rate ratio 0.846

$(0.725-0.987) ; p=0.0331$

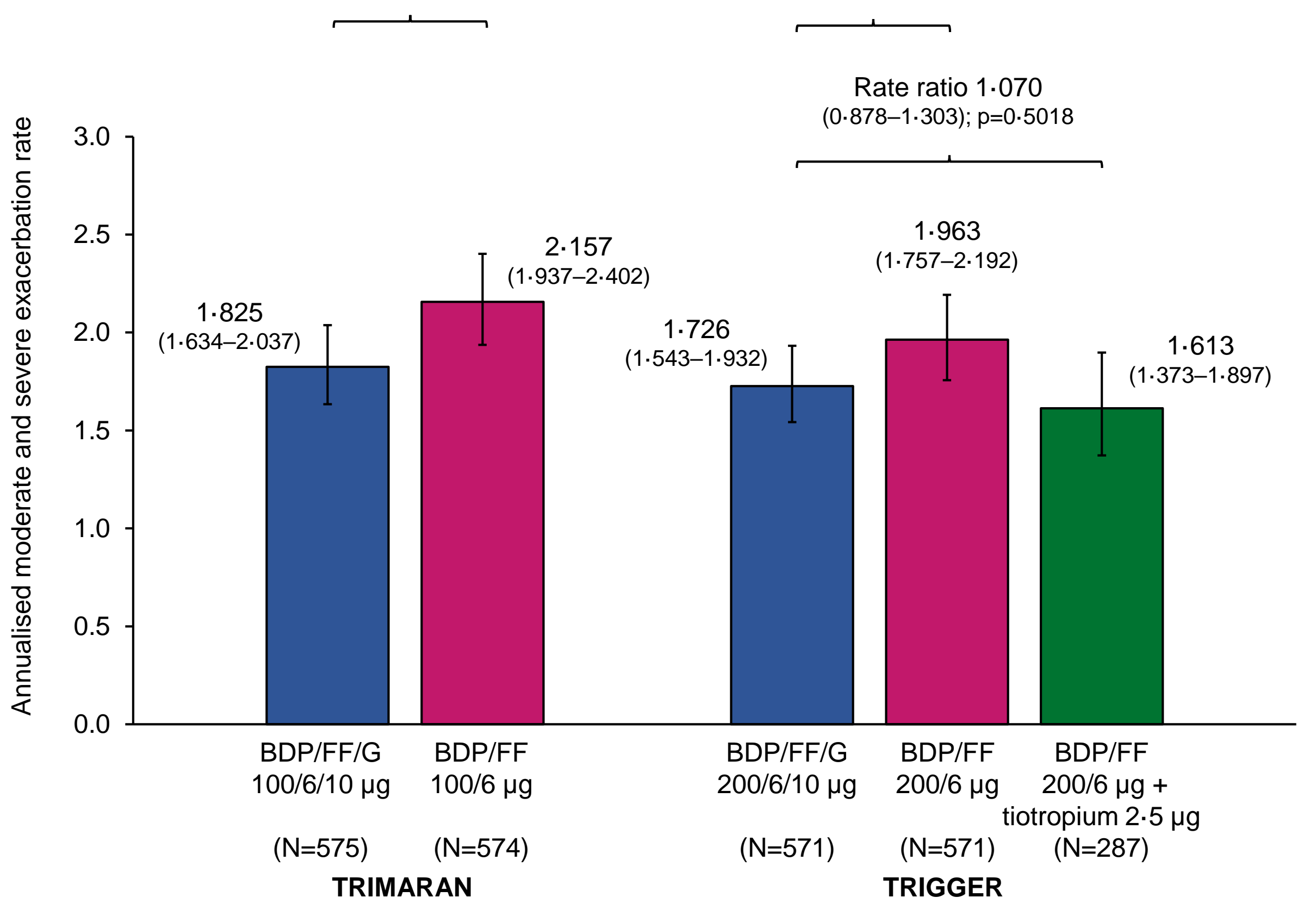

Co-primary: Rate ratio 0.880

(0.751-1.030); $p=0 \cdot 1102$

Rate ratio 1.070

$0.878-1.303) ; p=0.5018$ 
Key secondary: Difference $84 \mathrm{~mL}$

(40-129); $p=0.0002$

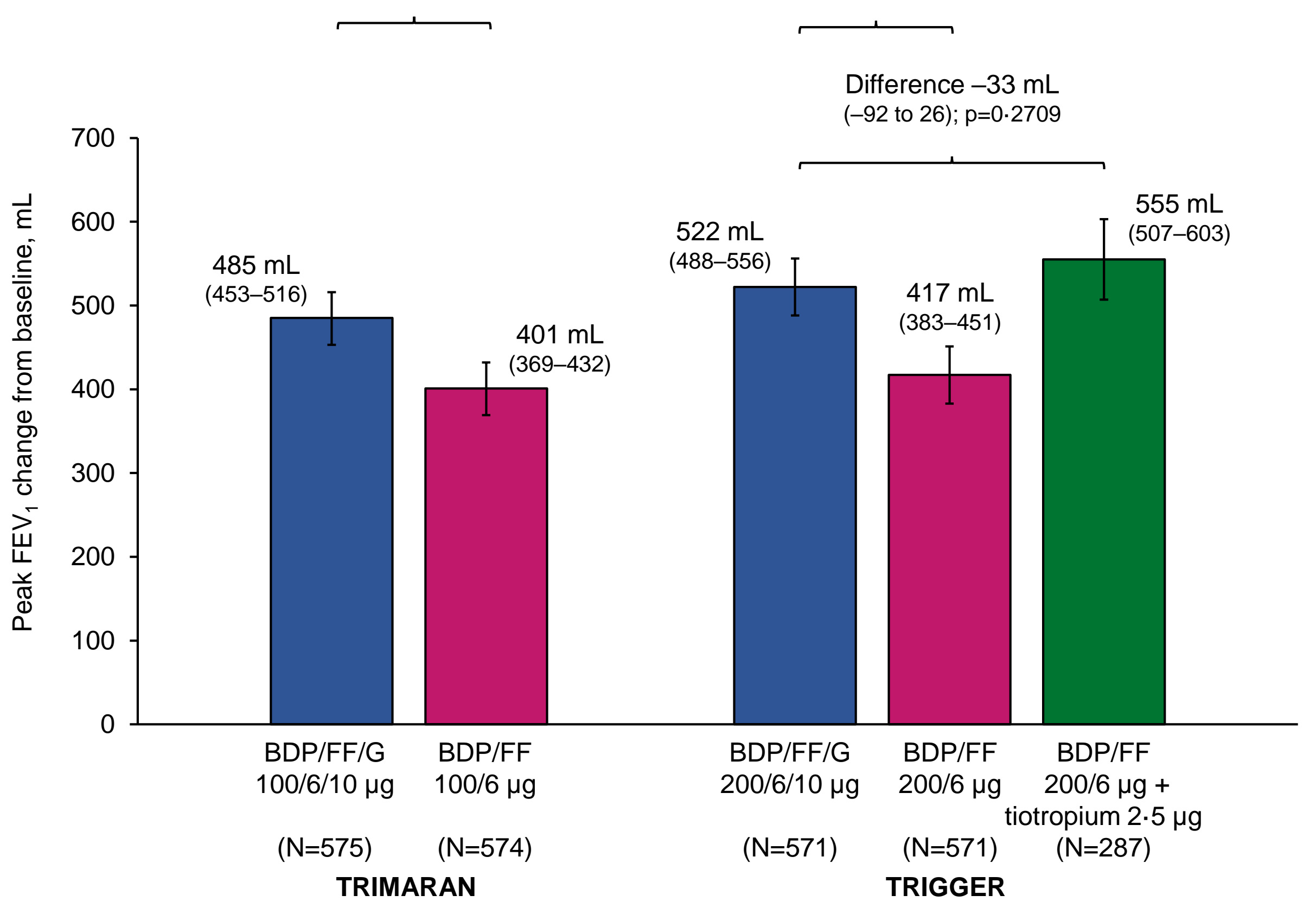

ondary: Difference $105 \mathrm{~mL}$

(57-153); $p<0.0001$

Difference $-33 \mathrm{~mL}$

$(-92$ to 26$) ; p=0 \cdot 2709$

$522 \mathrm{~mL}$

$88-556$

$\mathrm{mL}$

(3)-451) 
Key secondary: Difference $8.5 \mathrm{~L} / \mathrm{min}$

(3.6-13.3); $p=0.0006$

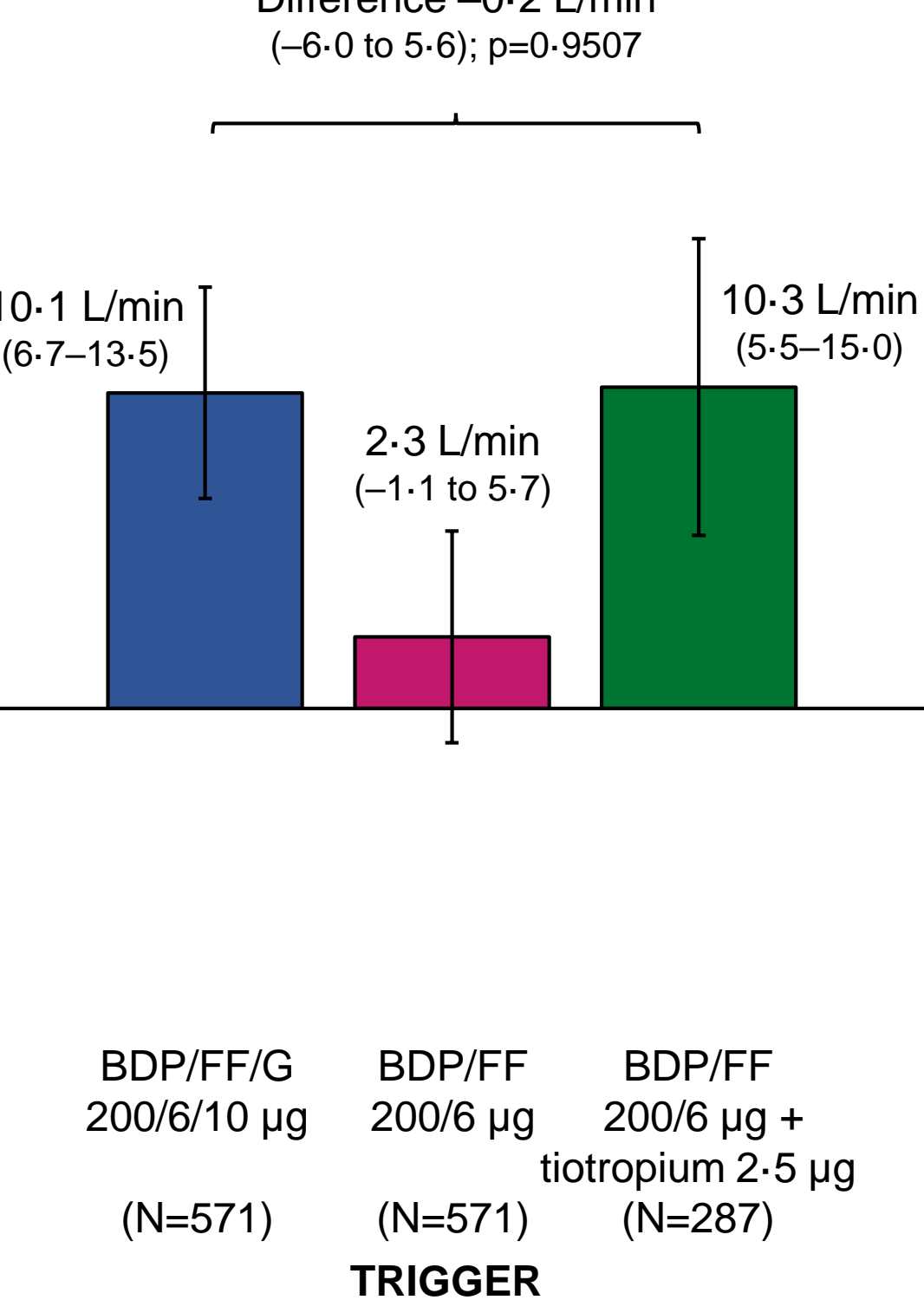

Difference $-0.2 \mathrm{~L} / \mathrm{min}$

-6.0 to 5.6$) ; p=0.9507$

$0 \cdot 1 \mathrm{~L} / \mathrm{min}$

$10 \cdot 3 \mathrm{~L} / \mathrm{min}$

$(5 \cdot 5-15 \cdot 0)$

Key secondary: Difference $7.8 \mathrm{~L} / \mathrm{min}$

$(3.0-12 \cdot 6) ; p=0.0014$ 
Key secondary:

Rate ratio 0.770

$(0.636-0.933) ; p=0.0076$

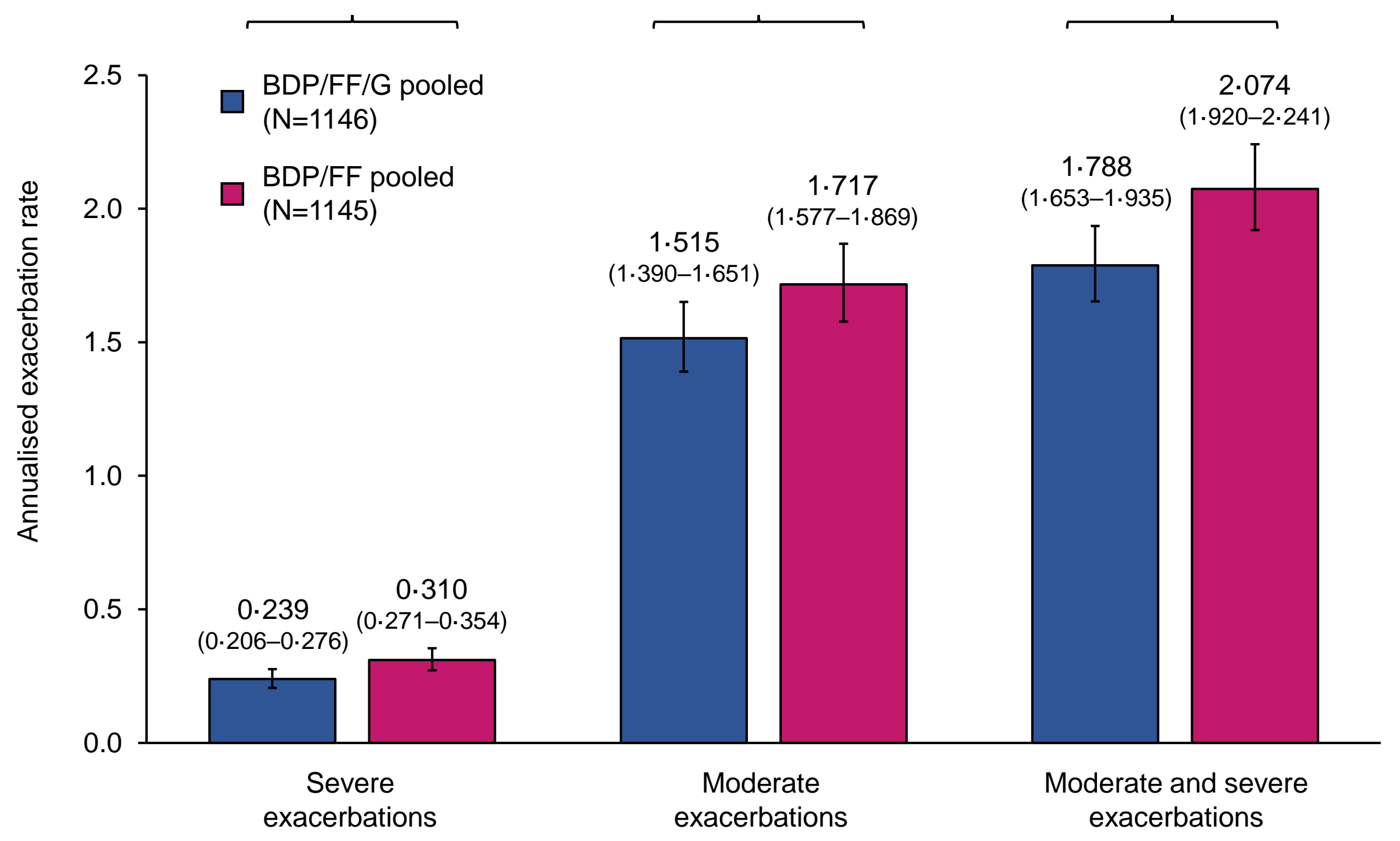

Rate ratio $0.883 \quad$ Rate ratio 0.862

(0.782-0.996); $p=0.0427$

(0.772-0.963); $p=0.0083$

\section{(1.920-2.241)}

exacerbations 


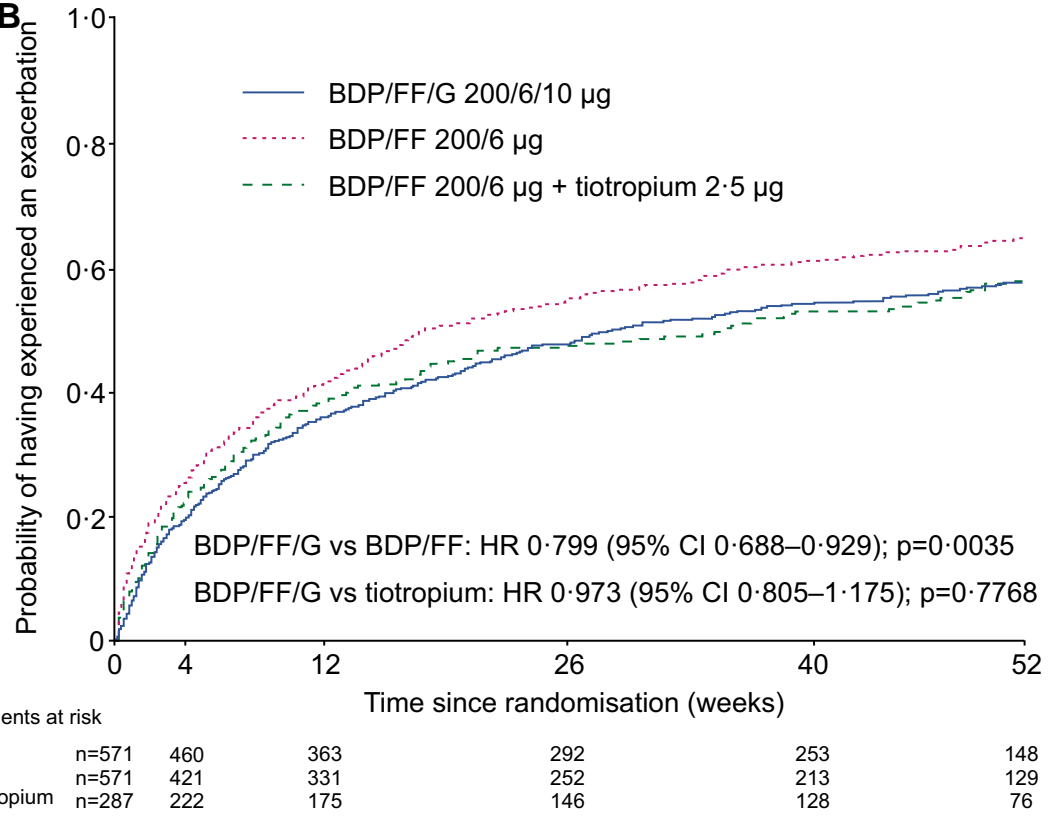

Number of patients at risk BDP/FF/G $\mathrm{BDP} / \mathrm{FF}$

$\begin{array}{ll}n=571 & 421 \\ n=287 & 222\end{array}$




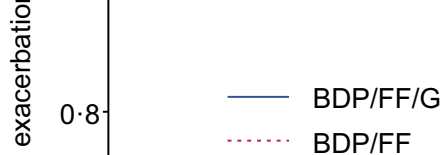

$\frac{5}{\pi}$

ఫ

U 0.6

은

$\frac{1}{\square}$

(1)

은 $0.4-\quad H R 0.788(95 \% \mathrm{Cl} 0.656-0.946) ; p=0.0106$

Number of patients at risk 

Supplementary Material
Click here to download S

Click here to download Supplementary Material: TRIMARAN and TRIGGER manuscript supplement (21 Aug 2019).pdf 